БРОДОВСКАЯ Елена Викторовна - доктор политических наук; профессор департамента политологии и массовых коммуникаций Финансового университета при Правительстве РФ (125993, Россия, г. Москва, ГСП-3, ул. Ленинградский пр-кт, 49; brodovskaya@inbox.ru)

ДОМБРОВСКАЯ Анна Юрьевна - доктор социологических наук; доцент кафедры социально-политических исследований и технологий Московского педагогического государственного университета (119991, Россия, г. Москва, ул. М. Пироговская 1/1; an-doc@уапdех.ru)

ПЫРМА Роман Васильевич - кандидат политических наук; доцент департамента политологии и массовых коммуникаций, заместитель руководителя департамента политологии и массовых коммуникаций Финансового университета при Правительстве РФ (125993, Россия, г. Москва, ГСП-3, ул. Ленинградский пр-кт, 49; pyrma@таil.ru)

АЗАРОВ Артур Александрович - кандидат технических наук; начальник отдела информатизации и связи администрации Центрального района Санкт-Петербурга (191167, Россия, г. СанктПетербург, Невский пр-кт, 176; artur-azarov@yandex.ru)

\title{
ГОТОВНОСТЬ СОВРЕМЕННОЙ РОССИЙСКОЙ МОЛОДЕЖИ К РЕАЛИЗАЦИИ ГРАЖДАНСКОЙ И ПОЛИТИЧЕСКОЙ АКТИВНОСТИ В ЦИФРОВОЙ СРЕДЕ
}

\begin{abstract}
Аннотация. В статье представлены результаты эмпирического анализа установок российской молодежи в сфере гражданской и политической онлайн-активности, полученные в ходе всероссийского массового опроса. Авторы анализируют отношение молодого поколения России к различным форматам гражданского и политического сетевого участия, а также изучают оценку молодежью проблем, связанных с распространением контента, дестабилизирующего социально-политическую ситуацию в обществе.

Ключевые слова: молодежь, интернет-коммуникация, социальные медиа, гражданская и политическая онлайн-активность, онлайн-анкетирование
\end{abstract}

$\mathrm{B}$ условиях повсеместного развития Internet of all одним из ключевых исследовательских вопросов является определение масштабов, характера и результативности влияния цифровых коммуникаций на гражданскую и политическую активность интернет-пользователей. Одна из кибероптимистических гипотез, принадлежащая аналитикам Google Э. Шмидту и Дж. Коэну [Коэн, Шмидт 2013], была построена вокруг идеи, что именно поколение $Z$, сформировавшееся в эпоху массового Интернета, будет обладать всеми преференциями цифровой эпохи и прежде всего - бо́льшим потенциалом политического влияния, чем их родители. Представленные в статье результаты прикладного исследования являются проверкой данной гипотезы на массиве данных опроса российской молодежи в возрасте 15-24 лет.

Дуалистичность влияния вовлеченности в интернет-коммуникацию на политическую активность зафиксировали в своем исследовании М. Ксенос и П. Мой [Xenos, Moy 2007: 710]. В свою очередь Дж. Кан, Д. Аллен и их соавторы отмечают, что цифровые коммуникации в первую очередь вносят фундаментальные изменения в политические ожидания и практики («мобилизация через сверстников») [Kahne, Middaugh, Allen 2014]. Близкие идеи выражает Э.Coen, с точки зрения которой молодые люди находятся в ситуации активного экспериментирования с гражданскими практиками в цифровой среде [Soep 2014]. Отечественные исследователи данной проблемы традиционно настроены более пессимистично по сравнению с западными коллегами. Так, В.В. Петухов и соавторы указывают, что социальные сети пока не выполняют роль триггера общественного и политического активизма [Петухов и др. 2014: 11].

Измерение готовности российской молодежи к реализации гражданской и 
политической онлайн-активности осуществлено в рамках всероссийского массового опроса, посвященного воздействию цифровых технологий на формирование профессиональной культуры. Среди исследуемых признаков отдельный блок отражал установки респондентов в сфере онлайн-активности по выражению своих гражданских и политических позиций:

- отношение к развитию онлайн-сетевых политических партий и движений;

- мнение о развитии онлайн-сетевых форм добровольческих/волонтерских организаций;

- отношение к развитию онлайн-сетевых форм протестных движений;

- мнение о политических ток-шоу/батлах/квестах/онлайн-играх;

- отношение к политической рекламе в период избирательных/политических кампаний;

- мнение о возможности голосования посредством интернет- и мобильных технологий;

- оценка степени серьезности проблемы онлайн-пропаганды национализма и другого контента, нарушающего закон;

- отношение к контролю со стороны государства над интернет-контентом.

Доминирующее значение параметра, указывающего на отношение российской молодежи к развитию онлайн-сетевых политических партий и движений, свидетельствует о нейтральной оценке опрошенными данной формы политической активности (см. рис. 1.). Почти каждые двое из трех респондентов равнодушны и безразличны к возможности развития политических онлайн-объединений, лишь 1/5 часть молодежи оценивает такую возможность политической активности позитивно. Вместе с тем каждый пятый опрошенный заявляет о негативном отношении к онлайн политическим организациям (партиям и движениям).

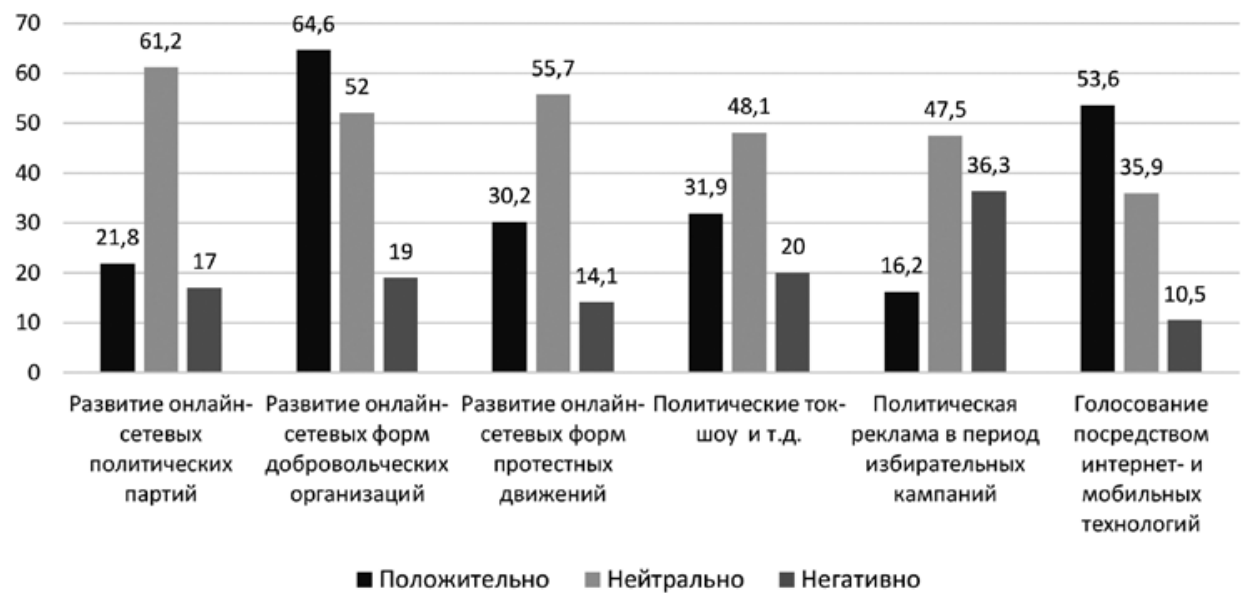

Рисунок 1. Отношение молодежи к различным типам гражданской и политической активности, в \%

Согласно данным исследования, взаимосвязь образовательного статуса опрошенной молодежи (школьник, студент или выпускник) с анализируемым показателем не столь очевидна. Вместе с тем обращает на себя внимание наиболее низкий процент, отражающий долю студентов, негативно оценивающих развитие онлайн-сетевых политических объединений $(14,2 \%)$. Если добавить 
несколько более выраженный процент студентов, положительно относящихся к рассматриваемой форме политической активности, то можно говорить о том, что в период обучения в высших учебных заведениях российская молодежь наиболее лояльно и оптимистично оценивает возможности цифровых технологий в развитии деятельности политических партий и объединений. Это может объясняться тем, что в период обучения в вузе в рамках социально-гуманитарного блока дисциплин формируются представления о возможностях реализации различных стратегий и форматов гражданской и политической активности, об использовании цифровых технологий в выражении своих гражданских и политических позиций.

Подчеркнем специфику отношения молодежи к развитию онлайн-сетевых политических организаций в зависимости от профессиональной стратегии, которую реализуют опрошенные. Сегментация респондентов по типу профессиональной стратегии была осуществлена с применением кластерного анализа (методом K-средних программного обеспечения SPSS Statistics 18.0). В результате получены три вида опрошенных, которые реализуют различные профессиональные стратегии: «идеалисты» (ориентированы на профессиональное становление и вместе с тем не готовы к активному и прагматичному выстраиванию карьерной траектории), «прагматики» (нацелены на активную профессионализацию, учитывают инструментальные характеристики выбранной профессии, готовы к рациональному моделированию карьерного трека), «традиционалисты» (обладают низким потенциалом профессиональной адаптации, не уверены в своем профессиональном выборе, пассивны в процессе освоения профессиональных компетенций).

Согласно данным исследования, «идеалисты» чаще, чем представители других профессиональных стратегий, положительно оценивают возможности анализируемой онлайн-активности $(29,0 \%)$. И напротив, среди «традиционалистов» больше всего скептиков по отношению к данной форме политической активности $(86,8 \%)$. Эти цифры объясняются спецификой социальных установок и позиций представителей различных профессиональных стратегий: «идеалисты» открыты новым формам социальной, профессиональной, гражданской и политической активности, прежде всего осуществляемой с применением цифровых технологий. «Традиционалисты», напротив, довольно равнодушны к различным возможностям цифрового пространства.

Такая же взаимосвязь прослеживается и в отношении других форм гражданской и политической активности: «идеалисты» и чуть реже - «прагматики» выражают наиболее позитивные взгляды в отношении онлайн-сетевых форм добровольческих (волонтерских) организаций, протестных движений, политических ток-шоу/батлов/квестов/игр, политической рекламы в период избирательных кампаний, возможностей голосования посредством интернет- и мобильных технологий.

Наиболее позитивную оценку российская молодежь дала такой форме онлайн-активности, как развитие онлайн-сетевых форм добровольческих/ волонтерских организаций (см. рис. 1): около 2/3 респондентов положительно относятся к данному типу сетевой активности. Это означает, что молодое поколение России высоко ценит волонтерство/добровольчество как социальное явление и считает, что их необходимо развивать любыми доступными методами, в т.ч. в формате онлайн-активности.

Важен тот факт, что к протестным формам онлайн-активности опрошенная молодежь довольно равнодушна. Так, лишь менее 1/3 респондентов позитивно оценили возможности сетевой протестной деятельности, а их доминирующая часть абсолютно нейтральна по отношению к данной форме 
активности. Эти цифры свидетельствуют о в целом невысокой готовности российской молодежи к участию в протестной онлайн-активности.

Похожее распределение значений характерно для такого параметра, как «отношение к политическим ток-шоу/батлам/квестам/ онлайн-играм». Такая форма политической активности привлекает примерно 1/3 молодежи, абсолютное большинство респондентов относятся к ней нейтрально либо негативно. Российское молодое поколение достаточно равнодушно к возможностям выражения своих политических позиций, взглядов онлайн. Наиболее негативные оценки молодежь дала такой онлайн-активности, как политическая реклама: более 4/5 респондентов относятся к политической рекламе нейтрально или негативно. Это говорит о слабом доверии молодежи к данному типу рекламы и низкому интересу к контенту данной рекламы.

Вместе с тем такая онлайн-активность, как голосование посредством Интернета и мобильных технологий, получила высокие оценки в анализируемом рейтинге респондентов. Более половины опрошенной молодежи позитивно относятся к тем возможностям, которые предоставляет дистанционное голосование. Это свидетельствует о высокой оценке молодым поколением России цифровых технологий, позволяющих облегчить реализацию электорального поведения.

Ответы на вопрос о серьезности проблемы онлайн-пропаганды национализма и другого контента, нарушающего закон, в целом говорят о низкой озабоченности молодежи данной болевой точкой современного общества: лишь $1 / 3$ молодежи категоричны в отношении данного контента $(33,1 \%)$, остальные респонденты выражают пассивную позицию, заключающуюся в игнорировании незаконного контента или вовсе указания на искусственность данного противоречия.

Данные исследования свидетельствуют о предпочтении молодежью такой ценности, как абсолютная свобода в сетевой среде, даже несмотря на угрозу распространения незаконного контента, формирующего деструктивные социальные установки и способствующего дестабилизации общества: 65,9\% молодых россиян убеждены в недопустимости контроля государства над интернетконтентом.

Резюмируя проанализированные результаты, отметим наиболее значимые характеристики готовности молодежи России к реализации политического и гражданского онлайн-участия. Наиболее позитивные установки российской молодежи в отношении гражданской и политической онлайн-активности касаются таких ее форм, как цифровое волонтерство/добровольчество, а также возможность реализации электорального поведения онлайн. Скептицизм российского молодого поколения связан прежде всего с такими форматами политической онлайн-активности, как политическая реклама, развитие политических объединений и политические ток-шоу. Наиболее позитивно к различным форматам политического и гражданского участия относятся «идеалисты» и чуть реже - «прагматики», открытые любым цифровым форматам социальной активности. Напротив, для «традиционалистов» характерно игнорирование возможностей онлайн-сетевых форм гражданской и политической активности. Наибольшую готовность к реализации политического и гражданского онлайн-участия демонстрируют студенты (по сравнению со школьниками и выпускниками), находящиеся в общественном пространстве вузов, ориентирующем обучающихся на активное выражение своей гражданской и политической позиций. Российская молодежь в целом недооценивает серьезность проблемы распространения незаконного контента и не готова осознать приоритет социальной стабильности 
и общественной безопасности перед ценностью абсолютной свободы в сетевой среде.

Статья подготовлена по результатам исследований, выполненных за счет бюджетныхсредств погосударственному заданию Финуниверситету.

\title{
Список литературы
}

Коэн Дж., Шмидт Э. 2013. Новый цифровой мир. М.: Манн, Иванов и Фербер. $368 \mathrm{c}$.

Петухов В.В., Бараш Р.Э., Седова Н.Н., Петухов Р.В. 2014. Гражданский активизм в России: мотивация, ценности и формы участия. - Bласть. № 9. С. 11-19.

Kahne J., Middaugh E., Allen D. 2014. Youth, New Media, and the Rise of Participatory Politics. URL: https://ypp.dmlcentral.net/sites/default/files/publications/YPP_WorkinPapers_Paper01_8.24.17.pdf (accessed 24.12.2018).

Soep E. 2014. Participatory Politics: Next-Generation Tactics to Remake Public Spheres. URL: https://ypp.dmlcentral.net/sites/default/files/publications/ Participatory_Politics_Next_Generation.pdf (accessed 24.12.2018).

Xenos M., Moy P. 2007. Direct and Differential Effects of the Internet on Political and Civic Engagement. - Journal of Communication. Vol. 57. Iss. 4. P. 704-718.

BRODOVSKAYA Elena Viktorovna, Dr.Sci. (Pol.Sci.); Professor of the Department of Political Science and Mass Communications, Financial University under the Government of the Russian Federation (49 Leningradsky Ave, GSP-3, Moscow, Russia, 125993; brodovskaya@inbox.ru)

DOMBROVSKAYA Anna Yur'evna, Dr.Sci. (Soc.); Associate Professor of the Chair of Socio-Political Research and Technology, Moscow State Pedagogical University (bld. 1, 1 Malaya Pirogovskaya St, Moscow, Russia, 119991; an-doc@ yandex.ru)

PYRMA Roman Vasil'evich, Cand.Sci. (Pol.Sci.); Associate Professor of the Department of Political Science and Mass Communications, Deputy Head of the Department of Political Science and Mass Communications, Financial University under the Government of the Russian Federation (49 Leningradsky Ave, GSP-3, Moscow, Russia, 125993; pyrma@mail. ru)

AZAROV Artur Aleksandrivich, Cand.Sci. (Tech.Sci.), Head of the Department for Information and Communication, Central District Administration of St. Petersburg (176 Nevsky Ave, Saint Petersburg, Russia, 191167; artur-azarov@ yandex.ru)

\section{THE READINESS OF MODERN RUSSIAN YOUTH TO IMPLEMENTFTION OF CIVIC AND POLITICAL ACTIVITY IN THE DIGITAL ENVIRONMENT}

\begin{abstract}
The article analyzes the attitudes of Russian youth to the civil and political online activity (discovered from the allRussian mass survey). The authors analyze attitudes of the young generation of Russia to various civil and political network participation dimensions, as well as the assessment of youth problems associated with the spread of content that destabilizes the socio-political situation in society. The paper identifies the relationship between the readiness of young people to civic and political online activity and such features as their educational status and professional culture. The results of the article may be of interest to the authorities, the Department of Youth Policy, political parties, non-governmental organizations aimed at the formation of political culture of youth.
\end{abstract}

Keywords: youth, Internet communication, social media, civil and political online activity, online survey 